\title{
PENSAR EM FILME
}

MIEKE BAL investiga a relação entre visualidade, amor romântico e capitalismo em sua transposição audiovisual de trechos de Madame Bovary

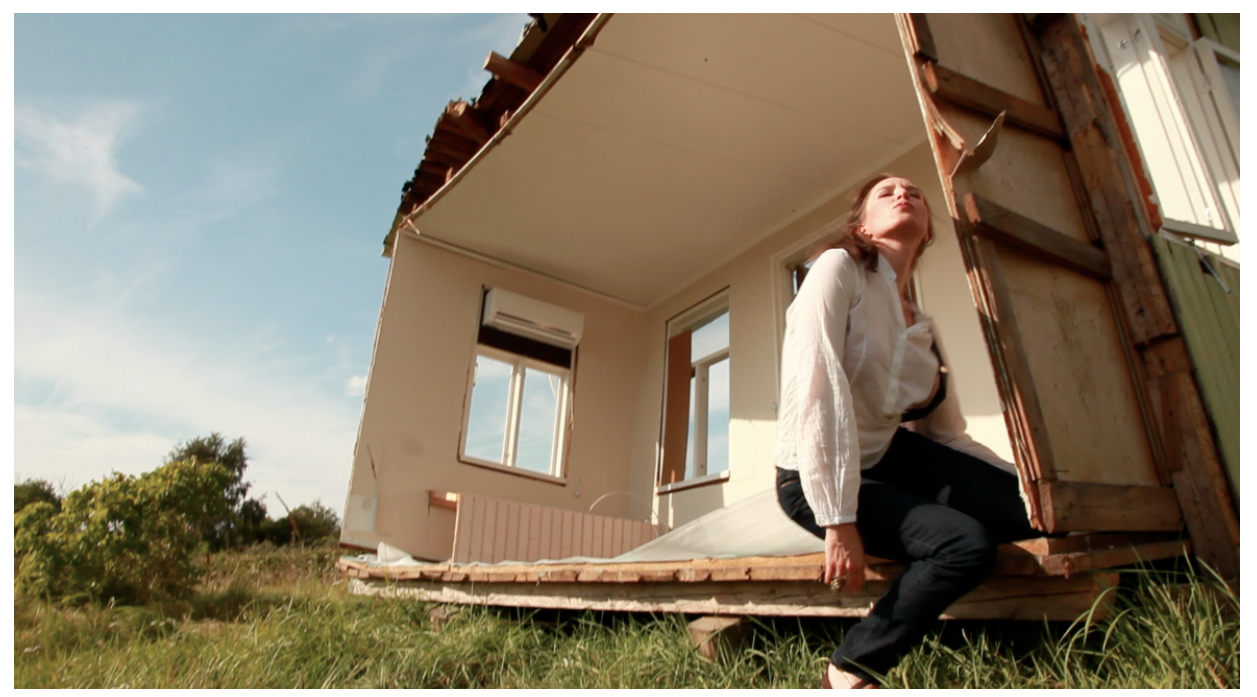

Cena do filme Madame B

Da sequência de abertura de nosso filme Madame B[1] mostra a ruína, por meio da perambulação de Emma em um campo vazio e na casa em ruínas. Essa ruína é o estado atual; o que vem em seguida nos levará de volta a esse ponto, em um movimento circular que se revela como um círculo vicioso. Dessa forma, a sequência de créditos na abertura já anuncia o modo da narrativa: baseado na circularidade, na repetição e no enfraquecimento do movimento narrativo linear. O projeto busca afastar a intermidialidade, ou tradução intermidial, da questão rasa da fidelidade e aproximá-la de outra forma de lealdade mais baseada na mídia.[2]

Na escola, Emma (interpretada por Marja Skaffari, Finlândia) fantasia 
durante as aulas sobre a realidade, mas é a melhor aluna na aula de canto e, conforme descobrimos mais adiante em um flashback, assiste a aulas extracurriculares de arte e etiqueta para ter elegância. Em outras palavras, ela é talentosa, e seus professores tentam ajudá-la, mas falta a ela a relação com o presente, o mundo e a realidade social. Como traduzir isso visualmente? Para tanto, encenamos maneiras de olhar específicas, às quais se ligam comportamentos sociais e se costumam atribuir juízo de valor.

Logo após a cena na escola, Emma cuida dos animais na fazenda de seu pai, a princípio com carinho, mas depois constata a monotonia da sua vida. Em seguida, seus passos em uma estrada vazia sugerem que ela está abandonando a fazenda a caminho de um tipo de vida diferente; $o$ movimento da câmera manual faz com que o espectador sinta os passos delas e veja o que ela vê. Quando então ela vê o fantasma de um homem (Charles, interpretado por Thomas Germaine, França), atrás das janelas, nós o vemos assim como ela o vê.

O que tentamos fazer com essa sequência foi criar uma forma visual de encontro onde as maneiras de olhar determinam, ao mesmo tempo, o começo de uma relação e a desigualdade no centro dela. Charles, também preso em uma rotina diária de solidão e trabalho, levanta os olhos e vê uma bela jovem. Ele olha para ela, durante várias manhãs seguidas, e seu modo de olhar pode facilmente ser considerado como um tanto voyeurístico. Ele permanece despercebido, especialmente quando olha do andar superior. Também parece ver mais do que é fisicamente possível, detalhando o corpo da jovem. Emma, depois de notá-lo, e perceber que ele a notou, parece ao mesmo tempo tímida e sedutora.

$\mathrm{Na}$ instalação que fizemos paralela a esse filme, colocamos o olhar do homem (Charles) que desperta o interesse da mulher (Emma) e viceversa em duas telas voltadas uma para a outra. O vídeo de sete minutos consiste em duas partes de $3 \mathrm{~min} 30$. Uma apresenta uma rotina sem acontecimentos; a outra dá início a uma mudança. A distância entre as telas será calculada para impossibilitar ver ambos os lados ao mesmo tempo. Além disso, para impedir que se olhe de longe, as telas ficarão tão próximas que tornarão a experiência de assistir a elas um tanto 
incômoda. Mas como eu posso dizer essas coisas sobre o que o espectador faz, sente e interpreta? Essa não é uma pergunta fácil; no entanto, é crucial se desejamos avaliar o impacto político da arte. Esse é o tema do projeto que acabei de finalizar, com três livros.[3]

Para responder a essa pergunta, preciso recuar um pouco. Lembro-me do meu primeiro encontro, há muito tempo, com a personagem Emma Bovary, de Flaubert, e da reação: "se ao menos ela tivesse o que fazer da vida!”. Ignorando as fortes limitações para as mulheres inscritas na pedra do Código Napoleônico, mas conhecendo muito bem os resquícios do meu próprio ambiente moral(ista) contemporâneo, em um período em que eu começava a trabalhar ao mesmo tempo em que cuidava de uma família, pensei que ela deveria ter sido mais ativa. É possível ter esse pensamento e, ao mesmo tempo, chorar amargamente. Ninguém está a salvo da atração perniciosa dos clichês ou, como Flaubert os chamava, idées reçues. Sem mencionar o anacronismo: encorajar uma mulher infeliz a trabalhar é algo dos dias de hoje, não de meados do século 19.

É, obviamente, uma reação muito ingênua; lembro-me dela agora, talvez até vermelha de vergonha. Essa vergonha é também uma oportunidade para influenciar a memória. Ao se identificar com personagens, mesmo com os insuportavelmente carregados, uma pessoa pode participar de suas aventuras, emoções, esperanças e decepções, tomar parte nos acontecimentos, até nas palavras que os descrevem. A identificação não depende do mérito do personagem. Nesse período de que me lembro, eu conseguia me envolver com eles; agora, no presente, consigo reconhecer o sentimento, revivê-lo, visto que está guardado em algum canto dentro de mim, e continua a ser sobredeterminado, camada por camada, por outras memórias.

Considero que é tarefa das Humanas, seja qual for o principal campo de pesquisas, entender, analisar e explicar a importância da arte - tanto do passado como do presente - para o mundo contemporâneo. Este projeto é parte dessa missão. Como acadêmica envolvida nessa missão, sempre tive a tendência, ao longo da minha carreira, de olhar para o que estava além do meu conhecimento. Essa atitude tornou o meu trabalho interdisciplinar pelo simples fato de que nunca conseguia acreditar na 


\begin{tabular}{l|ll}
\hline celeuma & número $3 \mid$ dezembro 2013 & dossiê \\
\hline
\end{tabular}

delimitação dos campos.

A literatura também contém imagens; pinturas não param no fim de suas molduras; e, como descobri em determinado momento, as imagens se movem assim como as pessoas. Portanto eu precisava trabalhar com esses limites impossíveis, ainda que consagrados pela tradição, com a maior responsabilidade possível. As imagens se movem não apenas porque as pessoas se movem diante delas ao visitarem museus ou virarem as páginas de um livro. O ponto mais fundamental é que as imagens se movem de formas que filósofos, sobretudo Henri Bergson, tentaram compreender. Eu estava interessada no movimento como uma integração do movimento físico e emocional, as trajetórias de afeto e percepção.

O livro Matéria e Memória, de Bergson, é fundamental para essa questão. Esse "ensaio sobre a relação do corpo com o espírito", como afirma o subtítulo, começa com a tese de que a percepção não é uma construção, mas uma seleção. O sujeito perceptivo faz a seleção tendo em vista seus próprios interesses. A percepção, do ponto de vista de Bergson, é um ato, do corpo e para o corpo. A seleção que é a percepção acontece no presente. Não são apenas os interesses do perceptor que a motivam, mas também as suas memórias. Charles olha para Emma, Emma para Charles, porque, mesmo antes de se verem, os dois tinham um interesse: digamos, escapar da monotonia.

Mas o espectador ou leitor também tem interesses. Um dos quais é gostar, ao mesmo tempo em que entende e aprende; e, talvez, ter experiências que não seriam possíveis de outra forma. E os espectadores somam suas próprias memórias, diferentes para cada um, à combinação de reconhecimento e novidade que é a experiência da arte. Ao fim do livro, Bergson escreve:

\footnotetext{
Na percepção concreta intervém a memória, e a subjetividade das qualidades sensíveis deve-se justamente ao fato de nossa consciência, que desde o início não é senão memória, prolongar um nos outros para condensá-los numa intuição única, uma pluralidade de momentos.[4]
} 
Essa coexistência de momentos (ou memórias) diferentes tem em si um aspecto espacial. O tempo-espaço resultante ganha forma na instalação de vídeo na presença simultânea - e, portanto, no movimento simultâneo - de múltiplas telas.

De acordo com Bergson, o espaço não é geométrico, como na visão renascentista; portanto, ele não é nem mensurável nem idêntico para ninguém que o percebe. Em vez disso, o espaço é uma sensação de espaço; e nossa sensação de espaço desenvolve, como Bergson chama, um “sentimento natural". Esse sentimento natural é heterogêneo e diferente para todos, dependendo do lugar em que estão. As telas múltiplas exemplificam a heterogeneidade com suas imagens em movimento assíncrono. Nas instalações em vídeo, o espaço é de fato heterogêneo, múltiplo, ao mesmo tempo real e fictício, subjetivo e "extensivo", ou dêitico. A história pode ser fictícia; o contato com ela é real.

Bergson considera o corpo como uma entidade material e, portanto, enxerga a percepção como uma prática material. Isso faz com que a concepção bergsoniana da imagem seja sinônima da imagem em movimento. Mas esse é um nível mais profundo em que as imagens se movem; ela se aproxima para afetar. A imagem em si — e não o seu suporte - está em movimento ao mesmo tempo em que é material. Ela implica ser plural e funcional - ela faz alguma coisa. Hoje, chamamos isso de performativo. $\mathrm{O}$ fato de que algo que ela faz pode ser individual, mas também social; assim, a imagem se torna politicamente efetiva. Em 1907, Bergson cunhou o termo "evolução criativa" para dar conta desse aspecto de movimento na imagem, que ocorre quando a imagempercepção, como Deleuze a denomina, se transforma em uma imagemafeto e faz com que o perceptor desenvolva uma prontidão para agir. Essa prontidão - e não a possível realização resultante - está na base do potencial político da imagem, do filme e da instalação de vídeo (figurativos).[5]

Por vários motivos, alguns biográficos, outros fortuitos, outros ainda intelectuais, eu me senti em determinado momento, há uns dez anos, compelida a explorar esses aspectos imbricados das imagens em movimento, em experimentos de filmagem. Meu desejo era entender a 
cultura que eu estava estudando em um nível "vivido", mais profundo, que era, também, mais complexamente contemporâneo. Eu queria entender como a cultura trabalha no presente. Isso me levou a um grupo de vídeos que chamo de documentários experimentais. Criamos um coletivo chamado Cinema Suitcase. Seus membros - dois dos quais ainda estão ativos, Michelle Williams Gamaker e eu - buscaram facilitar a autonarração de seus temas, sempre encontrados a partir de uma grande intimidade, em vez de construírem suas histórias para eles. Essa abordagem realça o caráter performativo da filmagem como um processo coletivo. Nossos filmes se caracterizam por empregar uma narrativa em voice-over e conter apenas o som do set. As histórias não são cronológicas, mas surgem de relações associativas, constituindo uma espécie de "estilo indireto livre".[6]

Comecei a pensar sobre como eu poderia empregar essa expressão audiovisual para entender mais, e com mais profundidade e nuances, $o$ que significa ser uma participante, mas também analisar a cultura contemporânea. Na prática, nunca, jamais me senti em conflito entre escrever e filmar. E, ao pensar sobre a contemporaneidade, o romance Madame Bovary - um livro há muito tempo preferido - se destacou. Para esse novo projeto, o primeiro impulso foi uma consideração sobre a importância crescente do econômico na cultura; ou, para ser mais precisa, a relação entre visualidade, amor romântico e capitalismo. Atualmente, com a crise econômica e suas consequências mundiais para indivíduos e famílias; e, relacionado a essa questão, o ressurgimento do feminismo, visto que, depois de deixar de lado o que acreditávamos ser uma batalha ganha, a necessidade do ativismo nesse aspecto se torna mais clara a cada dia. O conceito de "capitalismo emocional" da socióloga israelense Eva Illouz nos ajudou a perceber como era urgente refletir sobre essas conexões.[7]

Voltemos rapidamente à cena com que comecei: Charles vê mais da jovem do que poderia ver do ponto de vista lógico(físico); a imaginação toma parte. Dois olhares que são socialmente ambíguos passam a ter consequências quando se cruzam. No filme, o modo de filmagem é estruturado de maneira a estimular um carinhoso olhar conjunto. A atividade assim estimulada abrange uma compreensão da natureza dos 
dois olhares como diferentes e quem sabe complementares, e talvez ainda uma identificação parcial com um deles; ou com a dificuldade de escolher. Espera-se que essa dificuldade, por sua vez, apele para a autorreflexão do espectador, para a noção do que ver significa e faz. A essência é o despertar lento do olhar performativo: um olhar que age. Tudo surge desse olhar. Isso "explica”, em forma visual, o funcionamento social do olhar propriamente dito. $O$ fato de que a eficácia performativa de uma imagem dependa do olhar que se lance ao outro significa que a ontologia do visual é, fundamentalmente, dialógica.

É o que exatamente fizemos ao modificar e reduzir dessa forma o episódio das visitas frequentes de Charles à fazenda dos Rouault, les Berteaux; a descoberta da jovem menina e o despertar do desejo; a morte da primeira esposa de Charles e a proposta de casamento; o sim de Emma porque "ela pensou que tinha amor", como é dito em retrospecto? A essência dos capítulos 2 e 3 era, para nós, o olhar performativo. Afinal, tudo surge desse olhar. Isso "explica”, em forma imersiva-visual, o funcionamento do olhar em si, incluindo sua narratividade. Emma começa a existir quando Charles a vê - com tudo o mais que decorre desse ato. A decisão do pai, o procedimento da proposta de casamento na ausência da jovem, tudo isso - pequenos acontecimentos causados pelo olhar inicial - não nos pareceu atualizável nem importante, salvo a "cor local" temporal, isto é, histórica. Essa cor local-temporal é, para nós, uma distração, do tipo que prejudica a maioria dos outros filmes feitos sobre o tema. Por outro lado, com a ideia de confrontar os visitantes com um olhar performativo vivenciado, sentido, quisemos intervir, não apenas no criticismo de Flaubert, mas na teoria da arte e da cultura visual de modo mais geral. Desta última, a literatura é parte integrante.[8]

Outro exemplo de pensamento visual, como gosto de chamar, é a cena do casamento. Trata-se de um evento ao mesmo tempo público e privado: o resultado das duas cenas anteriores combinadas, porém, também, um evento que todos reconhecemos e, obedecendo à ideologia do amor romântico, consideramos um momento de felicidade. É, ainda, um dia de rituais, de comportamentos previsíveis; nesse sentido, é inexoravelmente impessoal. Pequenos incidentes ressaltam a ambivalência dos 
casamentos. Uma Estranha, presente sem ter sido convidada, que se comporta como uma pária social - nossa equivalente da "pedinte cega" de Flaubert - , faz uma aparição perturbadora na festa. Vestida de branco, surge como um duplo abjeto da noiva, deixando Emma insegura. $\mathrm{Na}$ festa, a Estranha canta uma música zombeteira e, assim, constrange a todos mais uma vez. Ela voltará a aparecer em diversas ocasiões, inclusive na morte de Emma.

Emma se sente sozinha em sua própria festa. Seus sonhos de menina começam a vacilar. Nós a vemos tímida, sem saber direito como se comportar, e esforçando-se muito para fazer o que se espera dela. É doloroso ver o quanto Emma se esforça para ser simpática. Essa cena, portanto, está relacionada a várias ambiguidades. Levanta questões de comportamento social, além de questões do comportamento público e privado, ritualizado e espontâneo. A beleza da noiva e das imagens desfigura a angústia dos acontecimentos, e vice-versa.O que torna um evento festivo? O que o torna triste? É esta a questão que essas imagens colocam, respondendo ao romance em vez de representá-lo. A trilha sonora, elaborando os mexericos dos convidados, levanta a questão de quem é o objeto de fofoca - a noiva ou a intrusa, mas certamente não o noivo ou o padre.

Outro exemplo é a cena da Recepção. No romance de Flaubert, escrito em uma época em que a nobreza já era obsoleta, mas ainda bastante presente, o último momento de ilusão de Emma de que seu casamento pode fazê-la feliz é o Baile no Castelo de Vaubyessard, promovido por um visconde. Consideramos esse momento importante, mas não era possível representar um baile como esse nos tempos atuais. Não porque buscávamos evitar anacronismos (muito pelo contrário, como explicarei adiante), mas porque as tensões sociais entre uma nobreza ainda pomposa e arrogante e os "plebeus" não teria seu impacto performativo nos dias de hoje. Hierarquias sociais distintas nos afetam com mais força. Pareceu-nos, portanto, que um equivalente seria uma recepção promovida por um poder comercial: a associação de empresas farmacêuticas. Essa é uma alusão ao personagem Homais, o farmacêutico cruel (interpretado por Mathieu Montanier, França), e a nosso trabalho prévio sobre a loucura, em que opomos o tratamento 
psicanalítico ao tratamento devastador adotado atualmente, com medicamentos.[9]

Como Charles exerce a profissão médica, ele foi convidado a uma recepção em Paris. Emma se entusiasma; sua primeira reação é perguntar ao marido se pode comprar um vestido novo. Essa é a primeira incursão dela nos engodos do capitalismo. Depois de interpretar mal a expressão "tênue de ville" no convite, ela exagera na roupa. Para ela, "cidade" significa glamour, e glamour custa caro. Mas o evento dos sonhos no Mundo Glamoroso se transforma em pesadelo. Os outros convidados ficam chocados quando a veem. Eles não acolhem nem Charles nem Emma em seus círculos de conversa, e tudo o que Emma faz para ser notada é um tanto quanto despropositado. Ela tem uma conversa canhestra com um homem, dança com ele, e tudo fica por isso mesmo mais solidão, isolamento e vergonha.

A cena trata dos estados de espírito, como uma força a favor e contra a narrativa. Os estados de espírito causam impacto no espectador e fazem com aceitem o movimento impulsionador da narrativa; contudo, quando empregados de certas formas, também podem se opor a esse mesmo movimento e, em vez disso, prejudicar o progresso linear, fazer com que os espectadores parem e, desse modo, criem círculos de pensamento em multiplicidade. Nossa tentativa era manter um equilíbrio tenso e instável entre uma visão crítica e empática de Emma. O contraste esperado entre o tédio em casa e o vendaval de entusiasmo na recepção é ilusório. Não é fácil "estar no mundo" e desenvolver e manter um estado de espírito específico.

A visualidade das imagens aumenta essa incerteza. Momentos de constrangimento angustiante atravessam as cores vivas das imagens. Primeiro, enfrentando seu ostracismo juntos, eles logo acabam sozinhos, quando Emma dança e Charles tenta não olhar, e, mais tarde, quando Emma come demais para compensar sua frustração, não consegue flertar com o "visconde" e, depois da única dança, está mais uma vez sozinha. Seguindo nossa concepção de narrativa circular, e também seguindo o emprego que Flaubert faz da predição simbólica na cena do Baile, aludimos à overdose de açúcar de confeiteiro e, posteriormente, vemos 
Emma aparecer como um fantasma, sem ser vista pelos outros, nem mesmo por Charles.

Para nós, o importante não é se o espectador conhece ou não o romance o bastante para ver essas insinuações como "leais" ao livro, mas sim aquilo que podemos chamar de "política de alusão". Para ver essas alusões ao fim, precisamos estar dispostos a abrir mão da organização narrativa e considerar a imagem como intrinsecamente dupla. Uma alusão não é uma metáfora; em vez de substituir uma coisa por outra, uma alusão engloba o aludido no que é visto. As alusões não operam em uma estrutura de "isso ou aquilo", mas sim em um modelo inclusivo de "isso e aquilo" ou "e também aquilo". A iconografia como método comprometido a decifrar sentidos ocultos tende a apoiar o modelo de metáfora, substituindo um sentido (digamos, ampulheta) por outro (memento mori); ou, no caso aqui, o que Emma coloca em seu arroz doce pode ser açúcar ou arsênico. Ou então a iconografia ganha um sentido falso como substituição metafórica, visto que funciona muito melhor quando considerada como alusão. Afinal, o elemento visual das imagens, incluindo as imagens estáticas que Bergson coloca em movimento, é resiliente em seu sentido "literal".

O açúcar representa a futura tendência de Emma à bulimia — parte de sua tendência de comprar mercadorias de luxo, comer demais e outras formas de gastos excessivos. A própria bulimia já pode ser um veneno por sua insalubridade, mas, em combinação com os gastos excessivos e passageiros, a destrói também do ponto de vista financeiro. Se, então, o açúcar é uma forma de veneno, também alude formalmente ao pó branco do arsênico. Com o uso do termo alusão como termo crítico, busco colocar em funcionamento a visão de Gilles Deleuze e Félix Guattari sobre a abstração conforme explicada em Mil planaltos e Kafka. O centro da visão deles é aquilo que chamei, no livro gêmeo Thinking in Film, de "endless andness": uma lógica cumulativa que evita substituir um efeito por outro, ou uma coisa visível por seu sentido alegórico.[10]

Nosso filme não é uma "adaptação fiel” do romance de Flaubert. É à contemporaneidade dele que desejamos ser leais. Fizemos essa obra para nosso presente, assim como ele a fez para o presente dele. Isso acarreta 
uma "traição" necessária do romance em muitos aspectos. No entanto, cultivamos o anacronismo como ferramenta indispensável para entender como uma obra de arte pode ser contemporânea por tanto tempo. A imagem está em transformação constante e, ao mesmo tempo, fica fora do paradigma do tempo. Portanto o anacronismo é a única maneira que o passado tem de permanecer vivo, ou mesmo de se tornar vivo.

Dois as pectos contribuem para essa sobrevivência do romance de Flaubert: seu tema e sua visualidade. Seu tema são as complicações entre os engodos combinados do capitalismo e do amor romântico. Assim sendo, ele liga o tempo de Flaubert ao nosso. Produto da segunda metade do século 19 mergulhado no fim da cultura vitoriana, Madame Bovary pode ser visto em relação a livros como Effie Briest (Alemanha), Anna Karenina (Rússia) e La Regenta (Espanha). Esses "romances de adultério", escritos por autores homens, contam sobre mulheres ambiciosas e tristes, muitas vezes tidas como "histéricas", e que invariavelmente acabam mal. A crítica literária britânica posterior escreveu um livro fabuloso sobre esses romances, Adultery in the Novel, que, publicado em 1979, ainda mantém sua relevância absoluta.[11]

O interessante é que há um anacronismo no próprio tema. Como esses romances apresentam a chama do desejo feminino e o horror que ele inspirava nos homens, eles alimentaram o pensamento freudiano que estava surgindo. A questão “O que querem as mulheres?” estava no ar e, embora Freud tenha se tornado seu porta-voz, ele não a inventou. À frente do seu tempo, Flaubert aliou, em Madame Bovary, a identificação com essas esposas infelizes a uma forte crítica ao capitalismo. Seu romance alimentou o tipo de questionamento que inspirou Freud, e o pensamento freudiano nos faz olhar para o romance de uma outra forma. Esse é o trajeto natural do anacronismo. Projetar o romance no passado vai contra seu traço mais característico, que é a contemporaneidade rigorosa. Nesse caso, fugir do anacronismo é um anacronismo. Por isso, nossa intenção foi fazer uma obra audiovisual que, ao mesmo tempo, atualizasse o romance e desse seu golpe político. [12]

Um exemplo óbvio é a cena da ópera. Nos tempos de Flaubert, a ópera 


\begin{tabular}{l|ll}
\hline celeuma & número $3 \mid$ dezembro 2013 & dossiê \\
\hline
\end{tabular}

fortemente romântica Lucia di Lammermoor, de Gaetano Donizetti, baseada em um romance de Walter Scott, apresentada pela primeira vez em 1839, era extremamente popular. Para Flaubert, isso era ideal, considerando o romantismo que ele via em toda parte ao redor dele e que buscava ridicularizar. Para manter nosso filme contemporâneo, usar a mesma ópera - como os filmes de Madame Bovary sempre fazem - é traí-lo por anacronismo. Mas a questão é mais complicada que isso. Escolher uma ópera que, hoje, se prestasse a ser ridicularizada de maneira igual perderia o ponto fundamental de Flaubert. Afinal, ele não estava ridicularizando a ópera; seu alvo era o engodo, o mal-entendido, a forma como o público, incluindo Emma e Léon, interpretavam mal o romantismo, indo além ao projetar nele seus próprios desejos egoístas.

Escolhemos a ópera Refuse the Hour (2012), de William Kentridge. Longe de ser ridícula, ela também ridiculariza questões políticas, sobretudo o colonialismo. E é isso que Emma e Léon não entendem. Assim, juntamos o interesse de Flaubert no mal-entendido, ao mesmo tempo em que usamos uma ópera que era muitíssimo diferente da que ele evocou. Queríamos uma obra de arte que, por sua própria qualidade, pedisse do público um apoio e também uma compreensão do grau da incapacidade de Emma de pensar em termos sociais. Além disso, selecionamos fragmentos que, assim como a excelente ópera de Donizetti, abordassem assuntos próximos de Emma. Não a paixão por um belo herói, mas a lembrança da monstruosidade de Medusa, sobre quem ela aprendeu na escola, e a advertência, na invocação de Perseu, de que um destino, uma vez escrito, não pode ser facilmente revogado. Na nossa concepção do filme, essas escolhas são afiliações com Flaubert e também "conversas" com sua obra. Trata-se de um anacronismo que é uma forma de pensamento histórico, e não o tipo de projeção irrefletida a partir do presente à qual os historiadores são, com toda razão, avessos. Dessa forma, o filme leva à reflexão nesses momentos, precisamente porque a substituição de uma ópera romântica por uma política contemporânea é um tanto quanto incongruente. É aí que está a performatividade, que pode ter impacto político.

Uma ferramenta comparável que o romance emprega e que buscamos emular para atingir a performatividade é ainda mais básica: o emprego 
da visualidade. A visualidade do romance se mostra em sua prosa excepcionalmente visual e, às vezes, até mesmo cinematográfica, de modo que, ainda hoje, vemos e testemunhamos visualmente o conteúdo do romance. Há muitos filmes baseados em Madame Bovary. Como a maioria são dramas históricos de época, eles são mais fiéis à história do que à forma como ela é contada - desconsideram a narrativa e sua dinâmica audiovisual específica. Nunca houve uma tentativa de pegar elementos da vida de Emma Bovary, representando momentos dela em vez de simplesmente representar sua história. No lugar de uma narrativa, nosso objetivo era criar um filme performativo. Buscamos alcançar isso pela lealdade ao cinema como forma de arte que daria a nossas imagens um potencial político fortemente cinematográfico.

A longa parte do filme que alterna entre conhecer seu amante Rodolphe, jantar com o marido Charles, a interferência do mundo exterior na forma de Hormais, o farmacêutico, e o caso dela com o comércio coloca o desafio que enfrentam todas as traduções de literatura em filme: como apresentar a rotina? Essa parte, em montagem paralela, representa a tensão entre acontecimento e rotina nas tentativas fracassadas de Emma de quebrar a rotina com o romance e as compras. Depois da sedução, a partir do momento em que ele a "possui", Rodolphe logo se cansa das tentativas crescentes dela de paixão e intimidade, suas exigências crescentes em relação a ele. Na rotina do caso, Emma vai aos poucos entendendo que o homem não está interessado no envolvimento a longo prazo, que ela vê como uma fuga para seu casamento exasperador. Momentos de paixão insincera alternam com mal-estar e uma compreensão crescente.

O emprego da audioimagem é outro exemplo do paradoxo da lealdade anacrônica, além de aumentar as camadas semióticas do filme. Nesse caso, a audioimagem é talvez a mais "literariamente relevante" para compreender a intermidialidade. No romance, há toda uma rede de sons - murmúrios, toques de sino, balidos de ovelha, mugidos de vacas, súplicas de Emma, conversas de amor e gritos - caracterizados pela indistinção. Eles são todos reiterativos, duráveis, rotina. Meu exemplo, aqui, deve se limitar ao uso do discurso direto para criar uma imagem que, em si, está em discurso indireto livre cinematográfico. Essa imagem 
sonora, fora do tempo da história, se torna a fonte da narração à sua própria maneira imagética.

Entre os milhares de sentenças narrativas que Flaubert criou ou tirou de discursos sociais ao redor dele, algumas se destacam como inesquecíveis, e pegamos algumas delas como pontos de partida para uma forma diferente de narração. Em um sentido, nossa concepção, que limita a maioria dos diálogos a citações literais, inclui também o oposto desse método restritivo. Em alguns casos, não demos aos atores uma citação para pronunciar, mas uma sentença com a qual operar - uma frase, uma expressão, um pensamento - , pedindo a eles que a usassem como ponto de partida para a improvisação. Às vezes, esse método gerou imagens sônicas: desdobramentos que constituem uma expressão baseada no sentido do conteúdo da narrativa que não é ilustrativa, mas que, logo após, encontra lugar em uma história mesmo sem ter uma localização textual.

Nosso exemplo é uma transmutação ou "visualização" da famosa sentença: "Sa conversation était plate comme un trottoir de rue" (A conversa dele era plana como o passeio da rua). É famosa com razão: devastadora para Charles aos olhos de Emma - se considerarmos a frase como um caso de discurso indireto livre -, mas, como Jonathan Culler argumentou, nada é menos definitivo do que precisamente esse discurso livre flutuante. De acordo com Culler, desprender as amarras do discurso e, dessa forma, impedir as fáceis atitudes preconceituosas é exatamente o projeto de Flaubert. E é também o nosso.[13]

A sentença curta é um excelente exemplo da economia de palavras. O uso do substantivo genérico "conversation", acompanhado por um verbo no imperfeito, que, nesse caso, nada tem a ver com o famoso uso extravagante que Flaubert fazia desse tempo verbal, mas expressa apenas a reiteração da rotina, implica, de maneira muito precisa, inúmeras palavras - um número infinito de palavras que acabam, como uma carga de pedras, caceteando alguém até a morte. Essa sentença precisava ser incluída não apenas como uma expressão narrativa de um não acontecimento - aquilo que Gérard Genette chamou de "silêncios de Flaubert" -, mas também como uma representação da monotonia que 
irá matar Emma. Ela causa, em outras palavras, uma inversão na economia narrativa, e na sua dinâmica entre narração e descrição, para nós, entre literário e cinematográfico: uma inversão que é, repito, necessária para sermos "leais" ao romance através de uma traição a ele. [14]

O caráter repetitivo da conversa plana implica que a sentença, a percepção que Emma tem de seu conteúdo e a derrocada em direção à aventura que vem a seguir - em nosso filme elas se alternam —, nada disso pode ser transformado facilmente em audiovisual, muito menos com a concisão de Flaubert, para a qual uma comparação foi o suficiente. É ao se esforçarem muito para fazer exatamente isso que a maioria dos filmes baseados em romances fracassa. Para experimentar, para fazer do filme um laboratório onde exploramos o que a narrativa é e pode fazer em vez de dar respostas prontas, apenas conversamos com os atores e depois pegamos a câmera sem nenhum ensaio.

Afinal, a qualidade da atuação improvisada (“jeu d'atelier”) está no espontâneo, na primeira vez - o oposto do que a sentença transmite. Devemos essa oportunidade à nossa boa sorte de trabalhar com atores absolutamente brilhantes.

Nosso objetivo era transformar a breve sentença narrativa, assim como o discurso direto repetitivo que a substituiu, em uma audioimagem em discurso indireto livre. Isso permite que o espectador tenha, em um nível intuitivo e sensorial, uma percepção dupla e conflituosa. A transformação do discurso narrativo, via discurso direto, em discurso indireto livre audiovisual foi buscada para implicar outra sentença narrativa curta que ecoa essa comparação: “C'était surtout aux heures des repas qu'elle n'en pouvait plus” (Era especialmente durante as refeições que ela não aguentava mais). Uma sequência narrativa conclui com esta sentença: "toute l'amertume de son existence lui semblait servie sur son assiette" (toda a amargura de sua existência lhe parecia servida no prato). Combinar as duas passagens curtas em uma imagem áudio(visual) faz jus à natureza dialógica efetiva, mas fracassada, das conversas monológicas de Charles.

O ator que representa Charles - além de Rodolphe e Léon —em nosso 
filme, o francês Thomas Germaine, havia simplesmente anunciado que gostaria de representar essas conversas repetitivas sobre quatro assuntos, ao longo de quatro jantares, marcados por diferentes roupas: o clima, o projeto de construir uma choupana no jardim, um paciente e a falta de gosto das framboesas naquele ano. Pode-se entender o surgimento da monotonia. A atriz que representa Emma, a finlandesa Marja Skaffari, por mais preparada que estivesse, só precisou se sentar ereta e ficar de boca fechada, exibindo no rosto o eco visual do discurso de Charles. Entre os dois, a imagem sônica funcionou, portanto, como a imagem performativa visual que descrevi anteriormente. As tomadas são longas e editadas com o mínimo de intervenção possível. As longas tomadas contrastam com o discurso exaltado.

Depois de ver o brilhantismo da encenação do tédio, decidimos editar quase exclusivamente com o rosto de Emma. É nele que a monotonia se inscreve - do ponto de vista performativo - com cada vez mais exasperação. É nele, também, que o discurso indireto livre pode tomar forma, ainda que, ou precisamente porque, seja Charles o único que fala. Em vez do rosto dele, vemos o ombro, turvo e obscurecido, como se ele assomasse sobre Emma como uma sombra. Assim como o primeiro contato dos dois olhares socialmente dúbios na primeira sequência, os dois personagens produzem a monotonia, que termina em horror, juntos. Como mal o vemos, sua fala constitui, de fato, uma imagem sônica no sentido estrito do termo.

Na história textual, Emma focaliza, ainda que o narrador sem identidade assuma o comando. É esse narrador que torna essa breve sentença ambígua. Portanto, precisa ser Emma a pessoa mostrada como prisioneira da conversa plana - plana como uma calçada, logo, esmagadora. Plano se iguala a pesado. E, de acordo com a concepção performativa do olhar, é o espectador que permite que ela demonstre sua monotonia e, ao fim, quando a monotonia se transforma em horror, grite. Afinal, é o espectador que, ao ver e sentir o horror, lê o rosto e, em certo sentido, permite que o tédio se torne visível. Um filme depende inteiramente dos seus espectadores para completar sua narrativa em potencial. Se um espectador fica impaciente, ele pode não passar pela mesma experiência quando Emma grita. Assim, a narrativa em si, no 
sentido de uma tensão crescente, pode se tornar plana.

Busquei dar alguns exemplos de como o filme constitui uma tentativa de ser esteticamente atraente e politicamente efetivo em uma relação intermidial com o romance de origem. E, para mim, como uma estudiosa da literatura de Flaubert, também corri um risco nas questões paradoxais de "lealdade" - melhor traduzida como "lealdade por traição". Meu objetivo neste artigo foi convencer vocês de que a efetividade em um domínio não é suplementar, tampouco contrária, à efetividade em outro domínio, muito pelo contrário. A arte é politicamente efetiva por causa, e por meio, de seu golpe artístico.

[1] (Mieke Bal \& Gamaker, Michelle Williams, Cinema Suitcase 2014).

[2] Este artigo se baseia em duas obras de arte, ambas intituladas Madame B: um longa metragem de 96 minutos, e uma série de 8 instalações de vídeo, com um total de 19 telas. O filme será lançado em 2014; as instalações serão exibidas inicialmente de dezembro de 2013 a fevereiro de 2014 no Museu Sztuki, em Lodz, Polônia; na Galeria Vaals em Tallin, em janeiro de 2014; na Post House, em Echero, Aland (Finlândia), em maio; e em Medellín e Bogotá, Colômbia, de junho a agosto de 2014.

[3] Nessa trilogia, examino a maneira como certas formas de arte podem ter efeitos políticos sem serem sobre política no sentido temático. What One Cannot Speak: Doris Salcedo's Political Art (Chicago: The University of Chicago Press 2010; atualmente traduzido para o espanhol); Thinking in Film: The Politics of Video Installation According to Eija-LiisaAhtila (London: Bloomsbury 2013); Endless Andness: The Politics of Abstraction According to Ann Veronica Janssens (London: Bloomsbury 2013).

[4] Bergson, Henri. Matéria e Memória - Ensaio sobre a relação do corpo como espírito. Trad. Paulo Neves. São Paulo: Editora Martins Fontes, 1990.

[5] Bergson, 1983.Creative Evolution. Trans. A. Mitchell. Lanham, MD: University Press of America. (Orig. pub. 1907.) Gilles Deleuze, Gilles. 1986. Cinema 1: The Movement-Image. Trans. Hugh Tomlinson and Barbara Habberjam. Minneapolis: University of Minnesota Press.

[6] Para títulos, clips e fotos, acesse http://www.miekebal.org/artworks/films/ (http://www.miekebal.org/artworks/films/).

[7] Illouz, Eva 2007 Cold Intimacies: The Making of Emotional Captalism. Cambridge, UK: Polity Press.

[8] Sobre a visualidade da literatura, ver capítulo "Caught by Images", a respeito da poesia da sobrevivente de Auschwitz Charlotte Delbo, em Ernst van Alphen, Art in Mind: How Images Shape Contemporary Thought (Chicago, the University of Chicago Press 2005).

[9] Ver nosso filme A Long History of Madness (2012), http://www.crazymothermovie.com/ (http://www.crazymothermovie.com/). [10] Gilles Deleuze and Félix Guattari, A Thousand Plateaus: Capitalism and Schizophrenia. Trans. Brian Massumi. London: Athlone Press 1987.

[11] Tony Tanner, Adultery in the Novel: Contract and Transgression.Baltimore, MD: The Johns Hopkins University Press 1979.

[12] Levou muito tempo para que um crítico acrescentasse aquele artigo indefinido 
essencial à questão de Freud .Shoshana Felman, What Does a Woman Want? Reading and Sexual Difference. Baltimore, MD: The Johns Hopkins University Press 1993.

[13] Jonathan Culler, 1974 (revised editions 1985; 2006). Flaubert: The Uses of Uncertainty. Aurora, Colorado: Davies Group.

[14] Gérard Genette, “Silences de Flaubert”, Figures. Paris: Editions du Seuil 1966.

MIEKE BAL é teórica da cultura, crítica de arte, videoartista e professora da Universidade de Amsterdã. A lista completa de seus trabalhos teóricos e artísticos pode ser encontrada no site http://www.miekebal.org/

(http://www.miekebal.org/)

Tradução de Guilherme Miranda. 